\title{
SOSIALISASI PENGGUNAAN E-LEARNING SEBAGAI MEDIA BELAJAR SISWA SMPN 29 PALEMBANG
}

\author{
Husnawati1), Imelda Saluza ${ }^{2)}$, Dewi Sartika ${ }^{3)}$, Maya Amelia ${ }^{4)}$ \\ 1), 2)Program Studi Manajemen Informatika, Universitas Indo Global Mandiri \\ 3),4)Program Studi Teknik Informatika, Universitas Indo Global Mandiri \\ Jalan Jend. Sudirman No. 629 Palembang, Kode Pos : 30129 \\ Email : uthy.51291@gmail.com ${ }^{1)}$, imeldasaluza@uigm.ac.id ${ }^{2}$, dewi.sartika@uigm.ac.id ${ }^{3)}$, \\ realmayamaknyak@yahoo.co.id ${ }^{4)}$
}

\begin{abstract}
ABSTRAK
Seiring dengan perkembangan dunia teknologi informasi dan komunikasi (TIK) dalam bidang pendidikan, para pengajar maupun peserta didik dituntut untuk dapat menggunakan media elektronik. Penggunaan media elektronik sebagai salah satu upaya untuk meningkatkan proses pembelajaran dalam menumbuhkan minat belajar siswa. Melalui media elektronik atau yang lebih dikenal dengan ELearning siswa tidak hanya memperoleh ilmu melalui tatap muka di kelas, melainkan dapat diakses dengan mudah melalui perangkat elektronik kapanpun dan dimanapun. Di dalam laporan ini akan dipaparkan mengenai kegiatan pengabdian kepada masyarakat khususnya di SMP N 29 Palembang dalam rangka memberikan pengarahan kepada siswa mengenai penggunaan E-Learning sebagai media yang dapat menumbuhkan minat belajar siswa, sehingga proses pembelajaran akan lebih menarik dan materi yang disampaikan guru akan lebih mudah diterima oleh siswa.
\end{abstract}

Kata kunci : Teknologi, Media Belajar, E-Learning, Pembelajaran, Siswa.

\section{PENDAHULUAN}

Perkembangan teknologi informasi dan komunikasi (TIK) dalam bidang pendidikan saat ini sudah semakin maju. Seiring dengan perkembangan teknologi di era digitalisasi, berbagai usaha ditempuh untuk meningkatkan kualitas pendidikan dalam rangka meningkatkan perkembangan ilmu pengetahuan dan teknologi.

Pemanfaatan teknologi dalam dunia pendidikan sudah sangat meluas, mulai dari jenjang pendidikan dasar, menengah, sampai ke perguruan tinggi, meskipun variasi dan fokus pemanfaatannya berbeda-beda pada masing-masing institusi. Dalam upaya untuk meningkatkan mutu pendidikan di Indonesia, pemerintah selalu berusaha memperbaiki kurikulum pendidikan, dengan harapan perubahan kurikulum mampu membentuk sumber daya manusia yang berkualitas dan berguna bagi pembangunan bangsa.

Dalam menyikapi perkembangan serta kemajuan tekologi tersebut, para pendidik dituntut untuk dapat menguasai teknologi agar mampu mengembangkan materi-materi pembelajaran berbasis teknologi dan memanfaatkan teknologi sebagai media pembelajaran. Kekuatan TIK pada pembelajaran akan melahirkan konsep baru yang disebut dengan E-Learning (pembelajaran yang menggunakan media elektronik.

E-Learning merujuk pada penggunaan teknologi internet untuk mengirimkan serangkaian solusi yang dapat meningkatkan pengetahuan dan keterampilan [2]. Media belajar elektronik (E-Learning) di dalam perspektif pendidikan merupakan instrumen yang sangat strategis dan dapat menentukan keberhasilan proses belajar mengajar. Sebab keberadaannya secara langsung dapat memberikan dinamika tersendiri terhadap peserta didik [3][4]. E-Learning merupakan salah satu solusi dalam mempermudah peserta didik untuk memperoleh ilmu dimanapun dan kapanpun menggunakan perangkat mobile.

Kemajuan teknologi juga telah memungkinkan memanfaatan berbagai macam media secara bersamaan dalam bentuk multimedia pembelajaran. Penggunaan multimedia interaktif yang memuat komponen audio-visual (suara dan tampilan) untuk penyampaian materi pembelajaran dapat menarik perhatian siswa untuk belajar. 
Multimedia interaktif juga dapat memberikan kesempatan kepada siswa untuk melakukan eksperimen dan eksplorasi sehingga memberikan pengalaman belajar daripada hanya sekedar mendengar penjelasan guru. Agar proses belajar menjadi lebih mudah, informasi yang ingin disampaikan oleh pendidik dapat merangsang pikiran dan minat anak didik, proses pembelajaran menjadi lebih menyenangkan, serta pembelajaran dapat dilakukan dimana saja dan kapan saja.

Dalam rangka melaksanakan salah satu tri dharma perguruan tinggi yaitu pengabdian kepada masyarakat, maka Dosen Fakultas Ilmu Komputer, Universitas Indo Global Mandiri Palembang berinisiatif memberikan Sosialisasi Penggunaan E-Learning Sebagai Media Belajar Siswa SMPN 29 Palembang, dengan harapan dapat menumbuhkan minat belajar siswa sekaligus memberikan himbauan kepada siswa untuk aktif dalam memanfaatkan E-Learning sebagai media belajar.

Tujuan yang akan dicapai dari program ini adalah memberikan sosialisasi dan pengetahuan bagi siswa sebagai penunjang kegiatan proses belajar khususnya untuk penggunaan E-Learning yang dapat menunjang prestasi siswa di dalam proses pembelajaran. Serta manfaat yang dapat diperoleh yaitu untuk mengembangkan tradisi keilmuan pada lembaga-lembaga pendidikan seperti sekolah, madrasah, perguruan tinggi dan sejenisnya serta mampu meningkatkan dan mengembangkan mutu dari proses belajar-mengajar.

\section{METODE PELAKSANAAN PENGABDIAN}

Kegiatan Pengabdian Kepada Masyarakat "Sosialisasi Penggunaan E-Learning Sebagai Media Belajar Siswa SMPN 29 Palembang" bertujuan untuk membantu siswa agar lebih kreatif dalam memanfaatkan media elektronik sebagai media belajar, sehingga kegiatan belajar dapat dilakukan tidak hanya melalui tatap muka antara siswa dan guru di dalam kelas.

\section{A) Waktu Kegiatan}

Persiapan yang baik akan memudahkan dalam pelaksanaan Sosialisasi Penggunaan E-Learning Sebagai Media Belajar Siswa SMPN 29 Palembang serta menghindari permasalahan yang akan mungkin terjadi. Hal yang terkait dalam persiapan meliputi:

1. Melakukan diskusi dengan tim pelaksana tentang kegiatan pengabdiaan Masyarakat yang akan dilakukan serta materi yang akan disampaikan, serta menetapkan jadwal kegiatan.

2. Pengajuan permohonan izin pada Dekan Fakultas Ilmu Komputer dan Kepala LP2MK Universitas IGM tentang kegiatan pengabdian pada masyarakat yang akan dilakukan.

3. Dekan Fakultas Ilmu Komputer dan Kepala LP2MK Universitas IGM menyetujui kegiatan tersebut dengan membuat surat izin pelaksanaan kegiatan pengabdian pada masyarakat.

4. Membuat Proposal kegiatan.

5. Mengajukan proposal pada Dekan Fakultas Ilmu Komputer yang telah ditandatangani ketua LPPM Universitas Indo Global Mandiri untuk melaksanakan kegiatan Pengabdian pada Masyarakat.

6. Mengajukan proposal pada Kepala Sekolah SMPN 29 Palembang Sumatera Selatan.

7. Persiapan materi yang disampaikan

Materi yang dipilih untuk disajikan adalah:
a. Situs E-Learning
b. Pembelajaran menggunakan E-Learning
c. Langkah-langkah pembuatan dan penggunaan E-Learning

8. Persiapan perlengkapan untuk presentasi

Komponen komputer beserta perlengkapan untuk digunakan dalam Sosialisasi Penggunaan ELearning Sebagai Media Belajar Siswa SMPN 29 Palembang sebagai berikut:

a. Komputer standar dengan sistem operasi windows

b. Kelengkapan lain seperti mouse, keyboard, printer dan projector.

c. Referensi dari beberapa media yang berbasis E-Learning.

9. Pelaksanaan Kegiatan.

10.Pembuatan Laporan Kegiatan

\section{B) Peserta}

Peserta Sosialisasi Penggunaan E-Learning Sebagai Media Belajar Siswa SMPN 29 Palembang diikuti oleh perwakilan Siswa dan Siswi dari SMPN 29 Palembang. 


\section{C) Proses Kegiatan}

Proses kegiatan dilaksanakan selama 1 Hari pada hari selasaa, tanggal 14 November 2017, pukul 10.00 WIB - 12.30 WIB di SMPN 29 Palembang. Adapun kegiatan yang dilakukan selama pelatihan seperti yang tercantum pada tabel 1.

Tabel 1. Jadwal Pelaksanaan Kegiatan Pengabdian Kepada Masyarakat

\begin{tabular}{|c|c|c|}
\hline Pukul & Materi & Nara Sumber \\
\hline $09.30-10.00$ & Registrasi & Mahasiswa \\
\hline $10.00-10.30$ & Pembukaan & Dosen Pelaksana \\
\hline \multirow{4}{*}{$10.30-11.30$} & \multirow{4}{*}{ Materi } & Husnawati \\
\hline & & Maya Amelia \\
\hline & & Imelda Saluza \\
\hline & & Dewi Sartika \\
\hline $11.30-12.30$ & $\begin{array}{l}\text { Sosialisasi penggunaan } E- \\
\text { Learning bagi siswa SMPN } 29 \\
\text { Palembang }\end{array}$ & Tim Pelaksana \\
\hline
\end{tabular}

\section{HASIL DAN PEMBAHASAN}

Beberapa kegiatan yang dilakukan adalah Presentasi Materi dan Sosialisasi penggunaan E-Learning sebagai media belajar bagi siswa SMPN 29 Palembang. Pada kegiatan pengabdian kepada masyarakat mengenai Sosialisasi Penggunaan E-Learning Sebagai Media Belajar Siswa SMPN 29 Palembang, disampaikan materi penggunaan media belajar e-learning berupa media online dengan situs Edmodo.com. Aplikasi dari situs tersebut dapat di unduh oleh siswa secara gratis melalui perangkat portable yang memiliki sistem operasi android maupun ios, apabila siswa ingin membuka media $e$ learning tersebut menggunakan perangkat PC, maka siswa dapat langsung mengakses media tersebut di website resmi Edmodo.com melalui perangkat browser yang tersedia.

Akun yang dapat dibuat siswa di dalam situs Edmodo dapat dibuat menggunakan email siswa masing - masing secara gratis, selanjutnya setelah siswa memperoleh akun, siswa dapat mengikuti kelas dan mendaftarkan kode kelas yang telah dibuat oleh guru mereka untuk tiap - tiap mata pelajaran yang mereka ambil, para siswa juga dapat mengunduh materi - materi belajar seperti buku buku, maupun gambar - gambar yang telah di upload oleh guru mereka pada masing - masing mata pelajaran. Siswa dapat mengerjakan tugas, kuis, ujian, maupun latihan - latihan yang telah diberikan para guru mereka pada situs e-learning tersebut dan siswa dapat melihat nilai mereka masing masing beserta passing grade nya sebagai tolak ukur kesuksesan mereka dalam menerima materi yang diajarkan oleh para guru.

Jumlah peserta yang hadir pada kegiatan pengabdian kepada masyarakat mengenai Sosialisasi Penggunaan E-Learning Sebagai Media Belajar Siswa SMPN 29 Palembang dihadiri oleh kurang lebih 40 siswa aktif dari masing - masing perwakilan kelas VII-IX. Kegiatan pengabdian kepada masyarakat mengenai Sosialisasi Penggunaan E-Learning Sebagai Media Belajar Siswa SMPN 29 Palembang dapat dilihat pada gambar 1, 2, 3 .
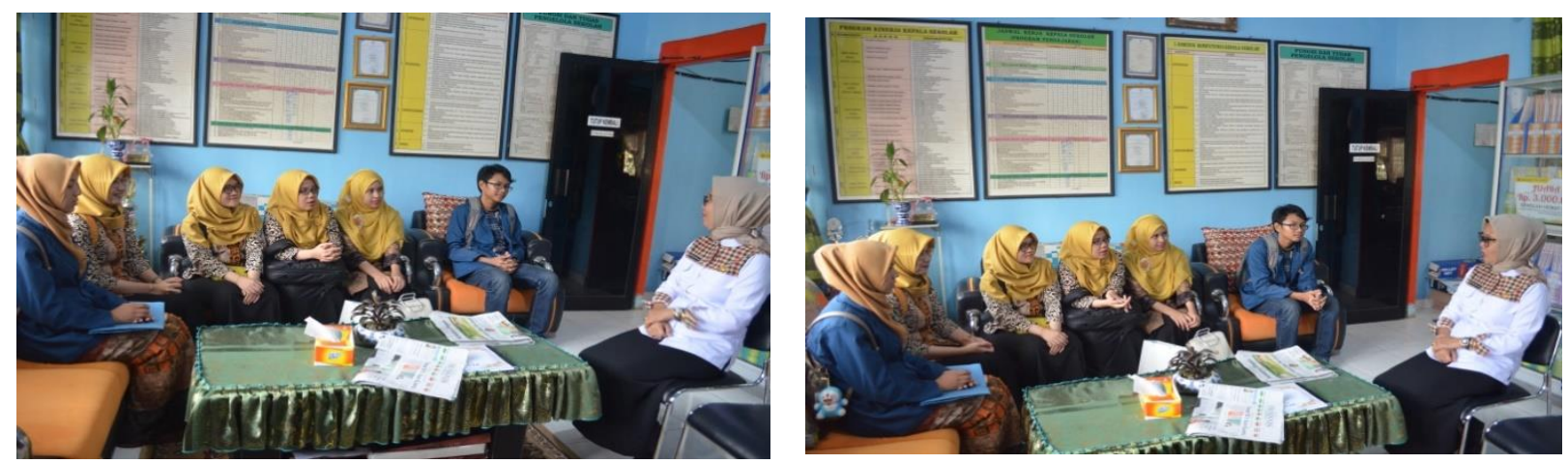

Gambar 1. Rapat Tim Pelaksana dengan Kepala Sekolah SMPN 29 Palembang 
Pada gambar 1, tim pelaksana yang terdiri dari 4 orang dosen Universitas Indo Global Mandiri dan 3 orang mahasiswa sedang melakukan rapat koordinasi terkait kegiatan sosialisasi yang akan dilaksanakan pada tanggal 14 November 2017. Pada rapat tersebut tim pelaksana menjelaskan maksud dan tujuan dari kegiatan pengabdian kepada masyarakat ini kepada Kepala Sekolah SMPN 29 Palembang. Tim pelaksana kegiatan mendapatkan sambutan yang sangat baik dari kepala sekolah SMPN 29 Palembang, yang mana pada saat ini masih dipimpin oleh Ibu Mardiana HM, S,Pd., M.Si.
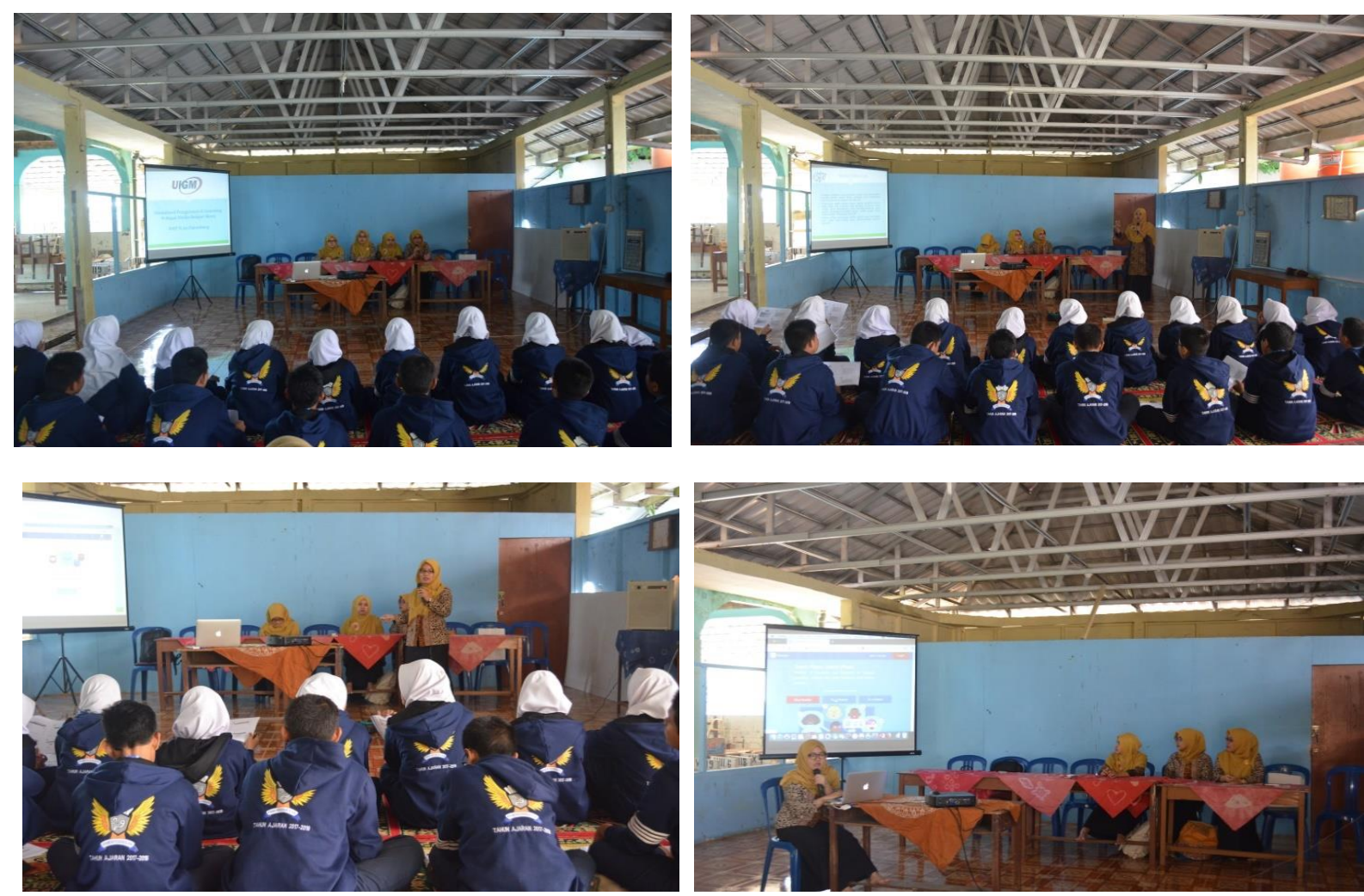

Gambar 2. Penyampaian Materi E-Learning Pada Kegiatan Sosialisasi Penggunaan E-Learning Sebagai Media Belajar Siswa SMPN 29 Palembang

Pada gambar 2, tim pelaksana kegiatan pengabdian kepada masyarakat sedang menyampaikan materi $e$ learning kepada para peserta sosialisasi, yaitu siswa dan siswi perwakilan dari kelas VII - IX SMPN 29 Palembang, dimana di dalam penyampaian materi tersebut dibagi menjadi 4 sesi penngajaran yang disampaikan langsung oleh tim dosen dari Universitas Indo Global Mandiri Palembang. Adapun peserta sosialisasi diberikan pengarahan secara langsung, dan materi berupa hard copy atau soft copy dalam bentuk file dan video, sehingga mereka bisa membaca ulang dan dapat langsung menerapkannya baik di sekolah maupun di rumah.
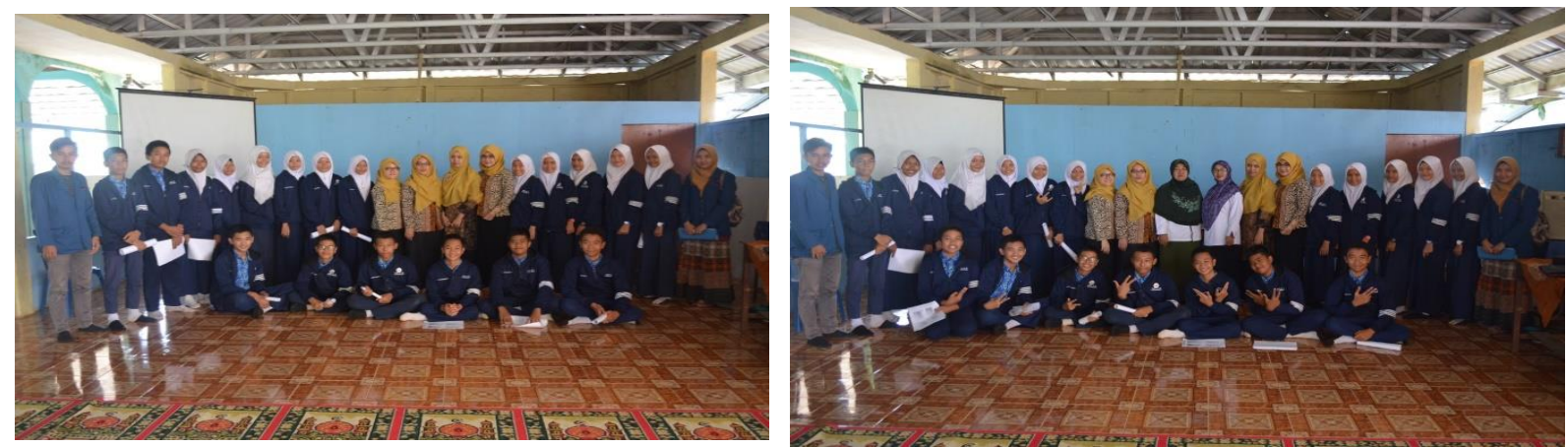

Gambar 3. Foto Bersama Siswa SMPN 29 Palembang sebagai Peserta Kegiatan Sosialisasi dan Para Guru SMPN 29 Palembang

Pada gambar 3, tim pelaksana telah menyelesaikan kegiatan pengabdian kepada masyarakat, sehingga pada akhir sesi dilakukan foto bersama peserta sosialisasi penggunaan e-learning yang merupakan siswa SMPN 
29 Palembang dan beberapa orang perwakilan guru dari SMPN 29 Palembang sebagai bentuk dokumentasi hasil pelaksanaan dan kenang - kenangan.

Hasil yang diperoleh dari pengabdian kepada masyarakat mengenai kegiatan Sosialisasi Penggunaan $E$ Learning Sebagai Media Belajar Siswa SMPN 29 Palembang antara lain :

1. Membantu siswa dalam membuat akun dan memiliki akses ke media belajar secara elektronik, sehingga siswa dapat belajar dimanapun.

2. Membantu siswa dalam meningkatkan minat belajar, sehingga siswa dalam proses belajar tidak hanya melalui tatap muka.

3. Mengaplikasikan E-Learning yang telah dibuat untuk melakukan proses pembelajaran di kelas serta dapat menumbuhkan minat belajar siswa.

\section{KESIMPULAN}

Kesimpulan dari hasil laporan kegiatan pengabdian pada Masyarakat yaitu; Kegiatan ini telah terlaksana dengan baik sesuai dengan tujuan dan mendapatkan sambutan yang baik dari SMPN 29 Palembang Sumatera Selatan. Kegiatan ini dapat memotivasi dan meningkatkan minat belajar siswa dalam memanfaatkan E-Learning sebagai media pembelajaran. Kegiatan seperti ini hendaknya dapat dilakukan secara berkesinambungan mengingat pengembangan media belajar menggunakan $E$ Learning sangat diperlukan untuk meningkatkan minat belajar siswa dan mampu memfasilitasi siswa, guru, dan orang tua/ wali siswa agar lebih interaktif.

\section{UCAPAN TERIMA KASIH}

Terima kasih kepada jurusan Manajemen Informatika, Teknik Informatika, dan Fakultas Ilmu Komputer Universitas Indo Global Mandiri, Lembaga Penelitian dan Pengabdian Masyarakat Universitas Indo Global Mandiri, Kepala Sekolah, para Guru beserta Siswa dan Siswi SMPN 29 Palembang.

\section{DAFTAR PUSTAKA}

Ramadhani. M. Efektivitas Penggunaan Media Pembelajaran E-learning Berbasis Web Pada Pelajaran Teknologi Informasi dan Komunikasi Terhadap Hasil Belajar Siswa kelas X SMA Negeri 1 Kalasan. pp. 1-30, 2012.

Sanderson, P, E. 2002. E-Learning: strategies for delivering knowledge in the digital age. Internet High. Educ 5(2) : 185-188.

Azhar. 2008. Media Pembelajaran. no. 1, pp. 1-13.

Yazdi, M. 2012. E-Learning Sebagai Media Pembelajaran Interaktif Berbasis Teknologi Informasi. J. Ilm. Foristek 2(1) : 143-152.

Georgiev, T. Georgieva, E and Smrikarov, A.2004. M-Learning- a New Stage of E -Learning. Int. Conf. Comput. Syst. Technol 1(1) : 1-5.

Aminoto, T and Pathoni, H. 2014. Penerapan Media E-Learning Berbasis Schoology Untuk Meningkatkan Aktivitas dan Hasil Belajar Materi Usaha dan Energi Di Kelas XI SMA N 10 Kota Jambi. J. Sainmatika 8(1) : 13-29.

Nurseto, T. 2011. Membuat Media Pembelajaran yang Menarik. Jurnal Ekonomi dan Pendidikan 8(1) : 19-35. 